in

v

()

\title{
Measuring Passive Engagement with Health Information on Social Media
}

Fatimah Alhayan, Diane Pennington (University of Strathclyde, UK) Sarra Ayouni (Princess Nora University, Riyadh) 


\section{Outline}

Objective

Key Concepts

Motivations

Related Work

Theoretical Model

Future Work 


\section{Objective}

Engagement with health content on social media enables effective health communication and health promotion strategies.

Healthcare professional and policymakers potentially benefit from the understanding of users' engagement role from a strategy focused on improving health care through messages on social media. 


\section{Engagement with Social Media Content}

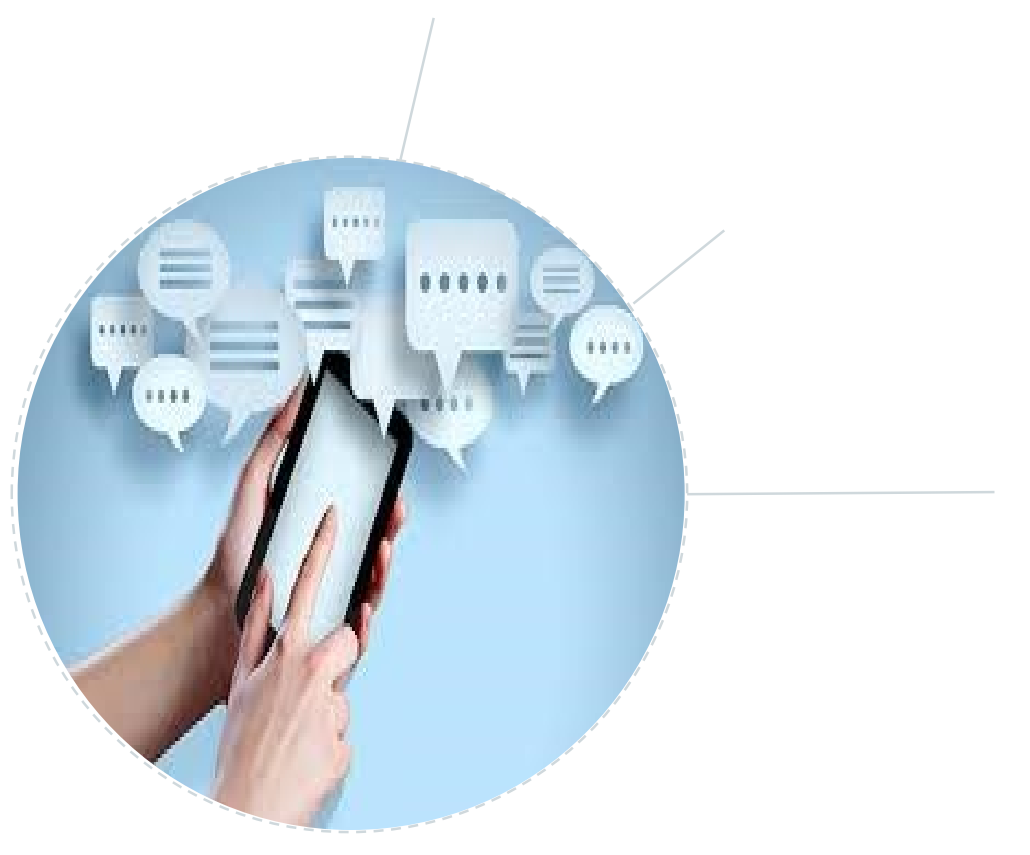




\section{User Engagement}

Little to no consensus exists on the definition of "engagement" on social media platforms.

The most common definition of user engagement has three dimensions: "the emotional, cognitive, and behavioural experience of a user with a technological resource that exists, at any point in time and over time" [1].

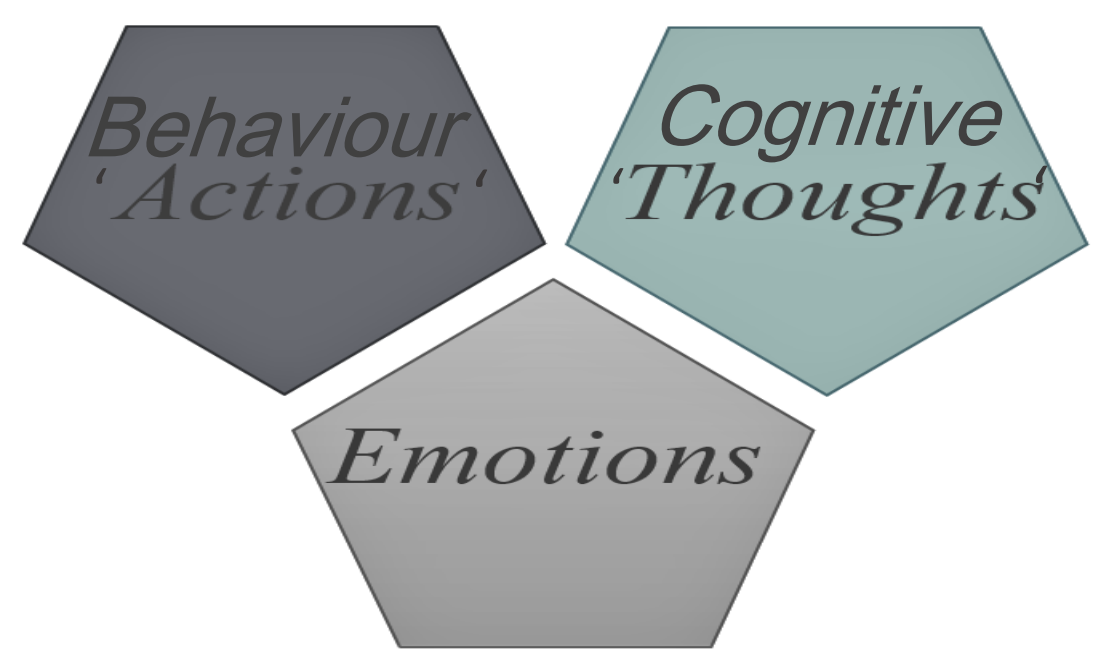




\section{User Engagement}

Engagement defined as only psychological, a 'state of mind'.

Passive engagement, considered by some researchers as a particular type of psychological user engagement.

It occurs even when no action is made online.

It create more objective data than subjective measurements. 


\section{Engagement Measurement}

The three dimensions capture the holistic nature of user engagement.

The ideal measurement would apply across all three types, if possible or necessary.

If this cannot happen, it is vital to use several measurements of the same type to assure reliable and valid data collection 


\section{Engagement Measurement}

A myriad of management tools have been developed to measure behavioural engagement experience.

Our focus on how the other two dimensions, the cognitive and emotional, have been measured and consider proposed changes in measurement especially in the non profit context (concerning public health)

We also present a theoretical model of measuring passive user engagement with health content on social media. 


\section{Motivation}

The Rule 90-9-1 (By Nielsen)

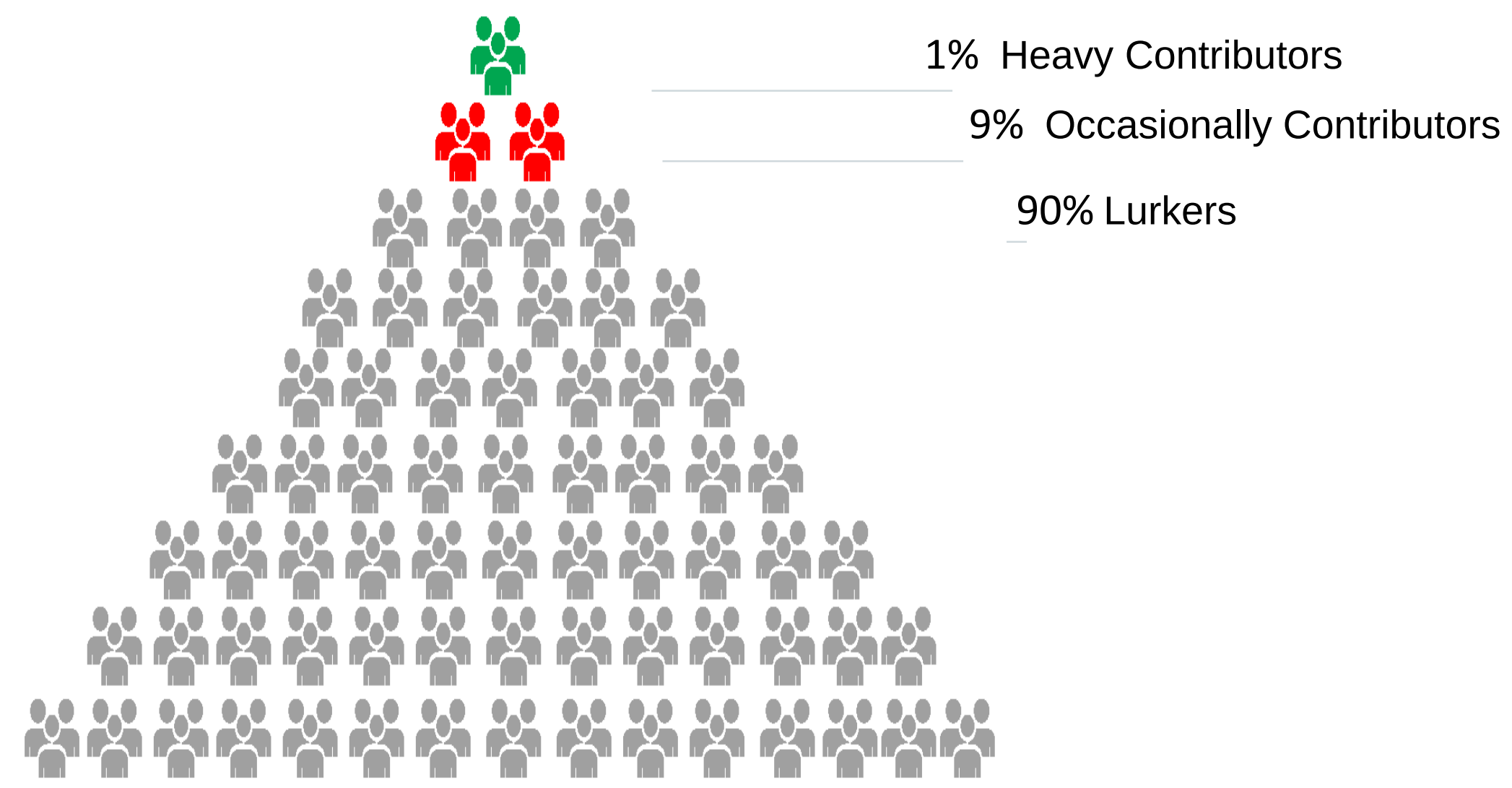




\section{Motivation (cont.)}

Social media content engagement can lead to offline behaviours like word of mouth, for example, are extremely important.

The value of developing psychologically pleasing content for a specific customer base is highly recommended.

It is noteworthy that metrics do not exist to measure social media content engagement and its potential for powerful influence. 


\section{Motivation (cont.)}

"What matters :earning attention on social media, not chasing numbers."

Gary Vaynerchuk 


\section{Motivation (cont.)}

Psychological engagement with social media content does not necessarily always lead to the social media behavioural interaction with content, and vice versa.

Social media behavioural interaction with content can generate large amounts of information in the form of:

user reviews and indicators (such as 'likes') allowing for informed decisions regarding trips, or online purchases (which can be false engagement ). 


\section{Measurements}

\section{How Passive Engagement Is Evaluated?}

There is no agreed upon measure for this type of engagement.

It is evaluated in relation to users' drivers and business outcomes.

Different motivations for user interaction with UGM. Some users want entertainment, others social interaction, and still others self-expression. 


\section{What motivates user participation and consumption on YouTube? (Khan, 2017)}

$>$ These researched behaviours provide insight for businesses seeking to make the exchange of entertainment value between content views and comments more attractive for new users.

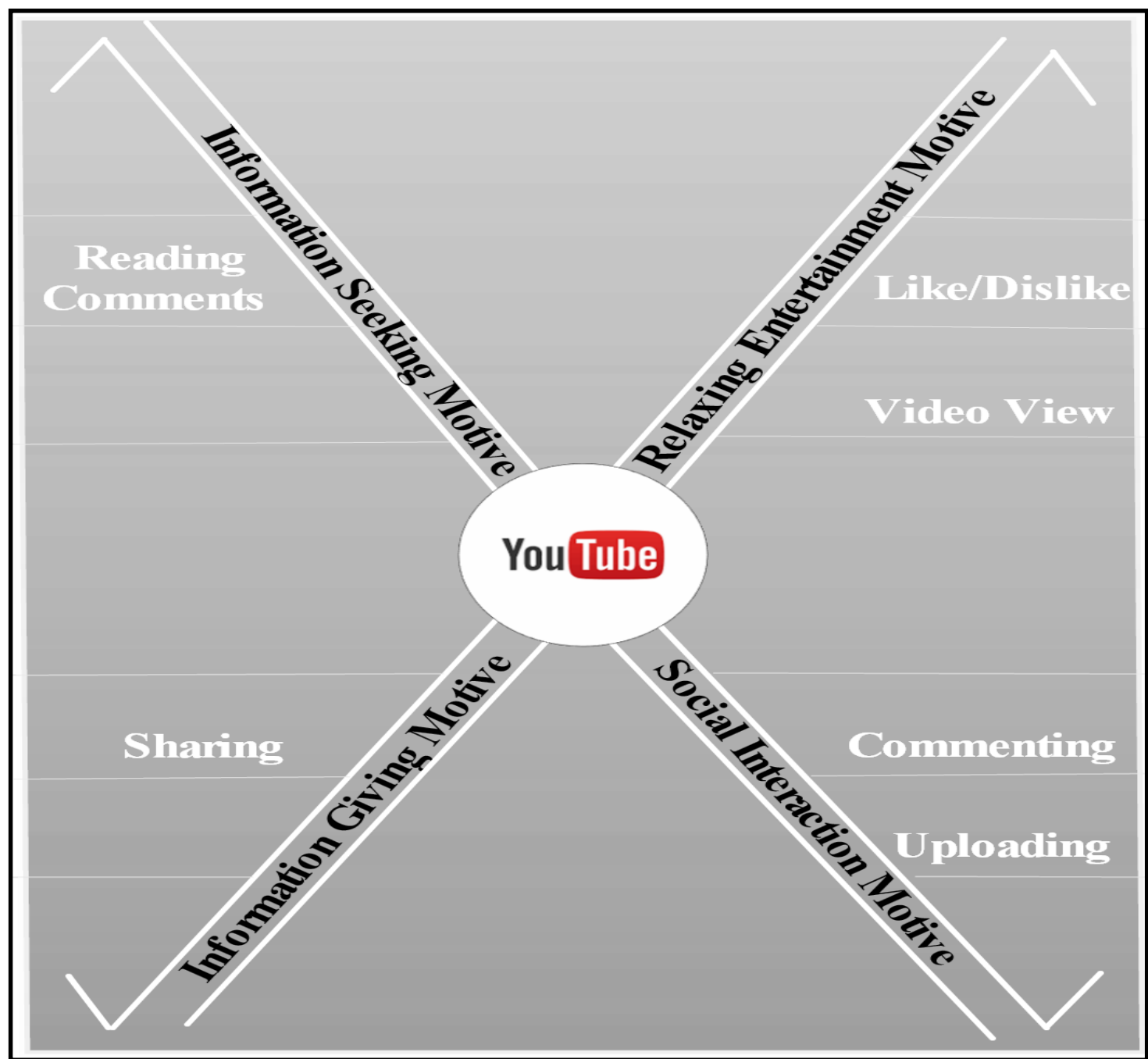




\section{AN APPROACH FOR MEASURING ENGAGEMENT WITH SOCIAL MEDIA CONTENT. (Sydral,2016)}

$>$ Brands and social media marketing practitioners could benefit from these drivers moving them beyond the arena of sharing and liking which are often inadequate.

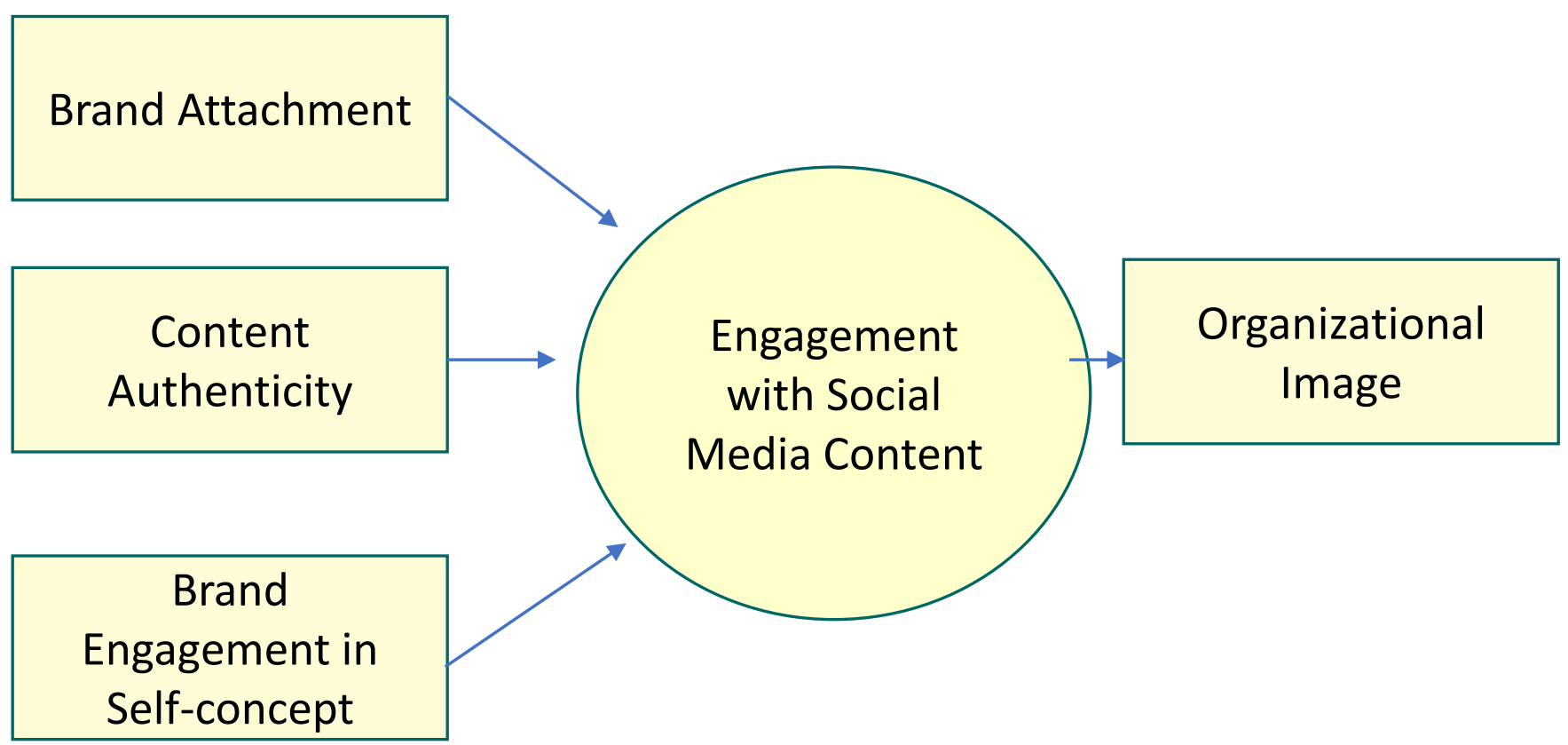

A conceptual model of drivers and an outcome of psychological engagement in the context of non-profit marketing 


\section{Engagement with Health Information on Social Media}




\section{Users health-information seeking via the Internet 2003-2017}

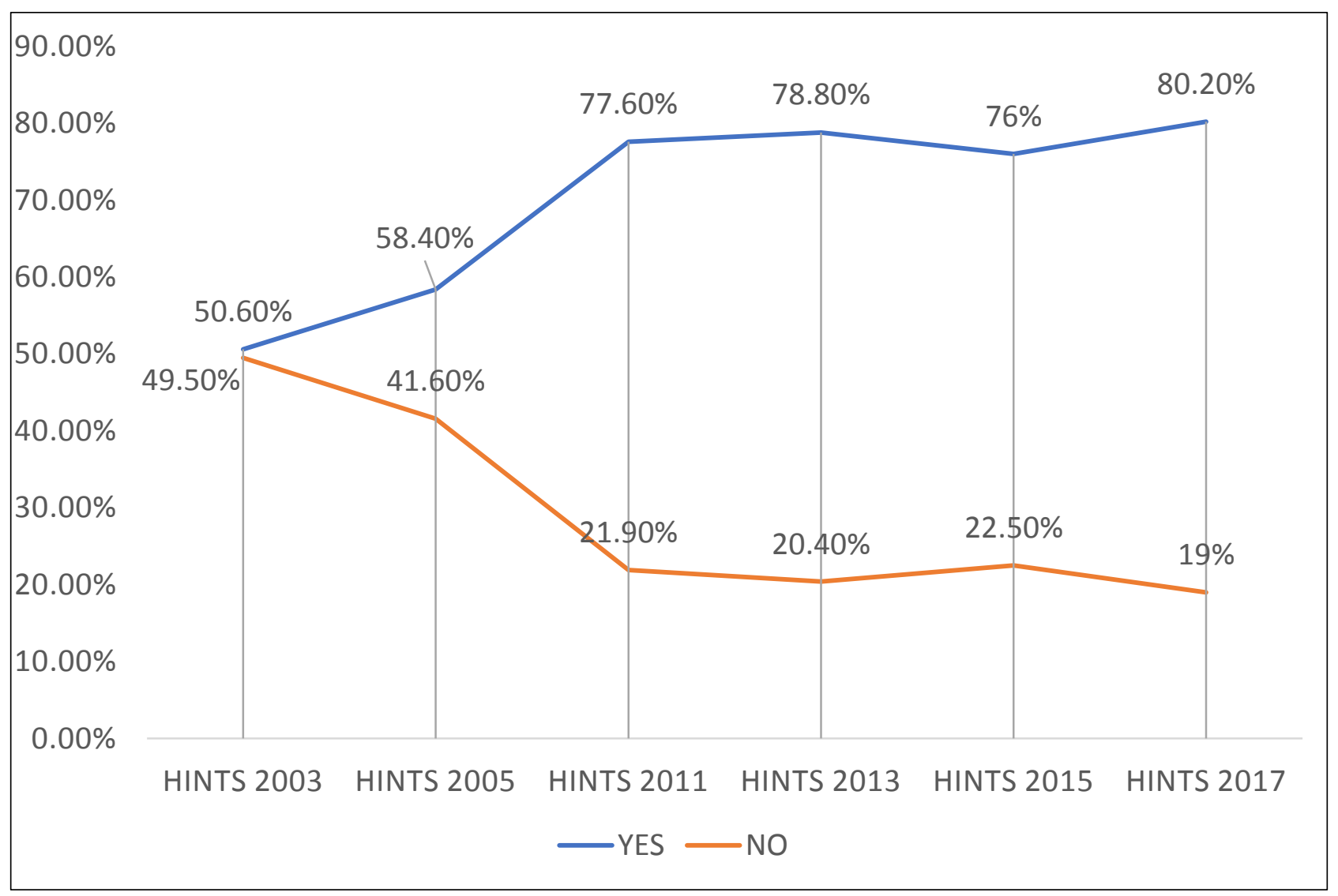

Percentage of People Looking for Health or Medical Information on the Internet Source: (HINT) Health Information National Trends Survey 


\section{Health Professional Presence on Social Media}

Freedom of sharing information on social media can inform or misinform the public.

The degree of influence that social media has as a source of information on a person's health decisions (e.g. vaccine or the formula-breast milk dilemma ) needs to be explored further.

The Health Information National Trends Survey 2012 (HINTS)

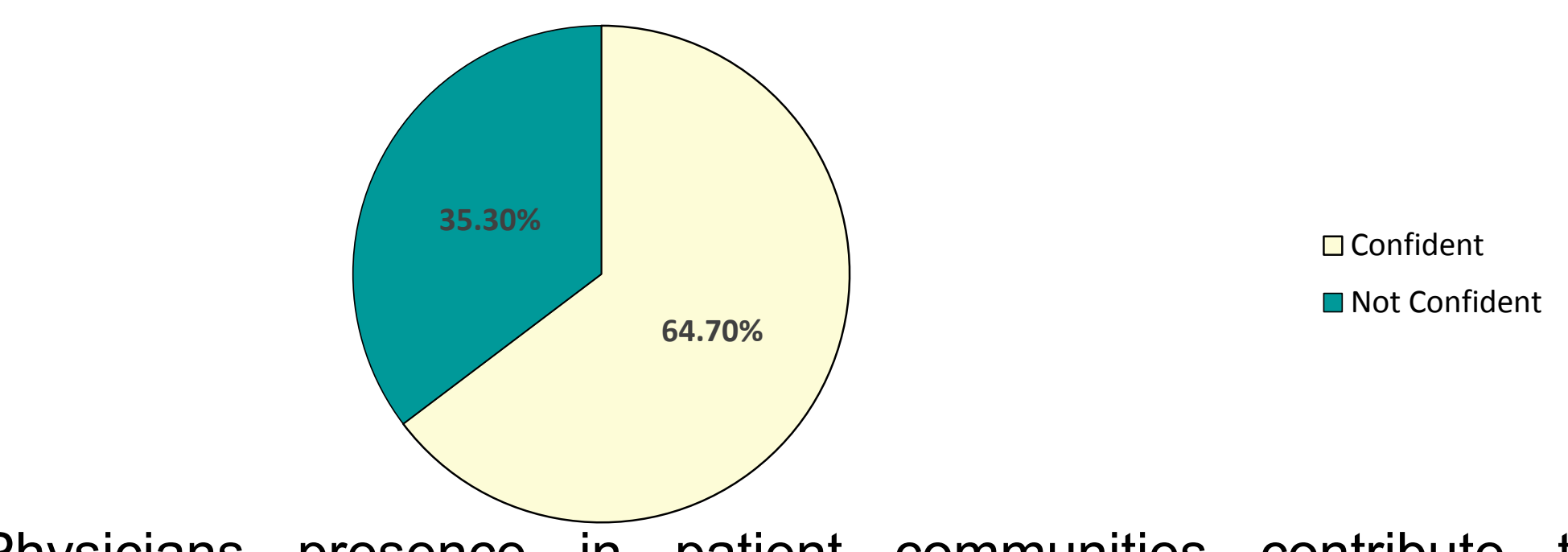

Physicians presence in patient communities contribute to correcting misconceptions. 
Personally, I feel to ignore the intersection between health care and social media is to potentially ignore our own relevance as a health care practitioner during the next decade

-Howard Luks

MD orthopedic surgeon and digital media and medicine specialist. 


\section{Marketing and Advertising}

Social media is utilized for marketing purposes by pharmaceutical companies, biotechnology firms, and manufacturers of medical equipment.

Consumer lose their trust in a source when it posts about its own drug or product.

Inappropriate and excessive use of drugs as well as an increase in money spent on high priced drugs resulted from direct advertising of health products. 


\section{Privacy Concerns}

Insufficient confidentiality exists in the social media space.

Users do not want to be discovered engaging on the web due to the stigma associated with certain health conditions.

The absence of online patient privacy and consent processes of health information on social media obstruct (or stop) user engagement. 


\section{Information- theoretical}

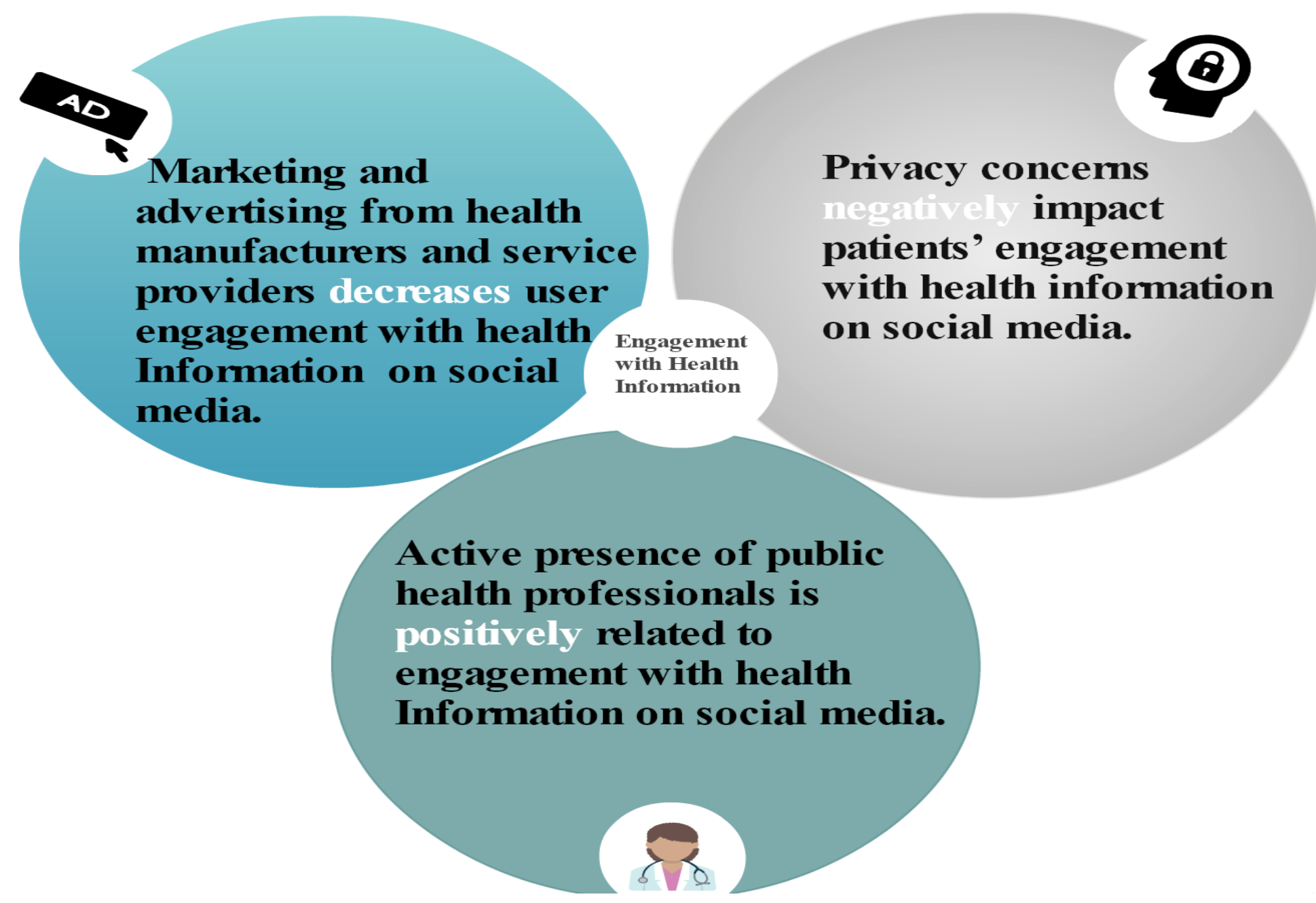




\section{Future Work}

Discover further drivers with essential outcome variables related to user engagement with health information on social media may be added.

Investigate and develop reliable methods of measuring passive engagement with health content on social media.

Compare interactive engagement with passive engagement related to the engagement of health information on social media.

Provide a framework that evaluates health content created especially for social media users, those that aim to engage users. 


\section{Thank You!}

Any questions? 


\section{References}

[1] M. Lalmas, H. O’Brien, and E. Yom-Tov, “Measuring User Engagement,” Synth Lect Inf Concepts, Retrieval, Serv, vol. 6, no. 4, pp. 1-132, 2014.

[2] H. L. O’Brien, "Exploring user engagement in online news interactions," Proc Am Soc Inf Sci Technol, vol. 48, no. 1, pp. 1-10, 2011.

[3] H. L. O’Brien and E. G. Toms, “What is User Engagement? A Conceptual Framework for Defining User Engagement with Technology," Commun Inf Lit, vol. 3, no. 2, pp. 80-90, 2008.

[4] S. H. Fairclough, "Fundamentals of physiological computing," Interact Comput, vol. 21, no. 1-2, pp. 133-145, 2009.

[5] B. Keller, A. Labrique, K. M. Jain, A. Pekosz, and O. Levine, “Mind the gap: Social media engagement by public health researchers," J Med Internet Res, vol. 16, no. 1 , pp. 1-8, 2014

[6] G. Shao, "Understanding the appeal of user-generated media: a uses and gratification perspective," Internet Res, vol. 19, no. 1, pp. 7-25, 2009.

[7] J. NIELSEN, "The 90-9-1 Rule for Participation Inequality in Social Media and Online Communities," Participation inequality: lurkers vs contributors in internet communities., 2009.

[8] H. A. Syrdal, "Exploring engagement with social media content," ProQuest, LLC, 2016.

[9] A. McCay-Peet, L. \& Quan-Haase, "Why engagement matters: Cross-disciplinary perspectives of user engagement in digital media," Why Engagem Matters CrossDisciplinary Perspect User Engagem Digit Media, pp. 1-222, 2016.

[10] M. L. Khan, "Social media engagement: What

motivates user participation and consumption on YouTube?," Comput Human Behav, vol. 66, pp. 236-247, 2017.

[11] L. Zhou, D. Zhang, C. C. Yang, and Y. Wang, “Harnessing social media for health information management,” Electron Commer Res Appl, vol. 27, pp. 139-151, 2018.

[12] D. C. DeAndrea and M. A. Vendemia, "How affiliation disclosure and control over user-generated comments affects consumer health knowledge and behavior: A randomized controlled experiment of pharmaceutical direct-to-consumer advertising on social media," J Med Internet Res, vol. 18, no. 7, 2016.

[13] B. A. Liang and T. K. Mackey, "Prevalence and global health implications of social media in direct-to-consumer drug advertising," J Med Internet Res, vol. 13, no. 3, pp. 1-10, 2011.

[14] F. G. and D. W. B. Ronen Rozenblum, “The role of social media around patient experience and engagement," J Med Genet, vol. 0, no. April, pp. 1-4, 2017.

[15] C. Holmberg, "If You can't beat It-Use It: Why and how clinicians need to consider social media in the treatment of adolescents with obesity," Eur J Clin Nutr, vol. 70, no. 9, pp. 977-978, 2016.

[16] D. S. Dizon et al., "Practical Guidance: The Use of Social Media In Oncology Practice," J Oncol Pract, vol. 8, no. 5, pp. e114-e124, 2012.

[17] K. Holmberg, K. Eriksson-Backa, and S. Ek, "Tweeting about Diabetes and Diets - Content and Conversational Connections," Commun Comput Inf Sci, vol. 450 CCIS, pp. 46-56, 2014

[18] H. Song et al., "Trusting social media as a source of health information: Online surveys comparing the United States, Korea, and Hong Kong," J Med Internet Res, vol. 18, no. 3, pp. 1-12, 2016.

https://hcsmmonitor.com/

https://www.pwc.com/us/en/health-industries/health-research-institute/publications/health-care-social-media.html

https://hints.cancer.gov/view-questions-topics/question-details.aspx?nq=1\&qid=757

Hesse BW, Nelson DE, Kreps G et al. Trust and sources of health information: The impact of the internet and its implications for health care providers: Findings from the first health information national trends survey. Arch Intern Med. 2005;165(22):2618-24. doi: 10.1001/archinte.165.22.2618 